\title{
The Industrial Use of Gold
}

\section{THE PAST DEGADE AND FUTURE PROSPECTS}

\author{
Christopher Glynn and Ronald Conley
}

Consolidated Gold Fields Limited, London

\begin{abstract}
The team responsible for the publication of Consolidated Gold Fields'
authoritative annual surveys of world gold supply and demand discusses

here the pattern of gold consumption by industry which has emerged over the past ten years. Although of unusual tenor for these pages, their review will interest readers involved with applications of the metal, both in production and research.
\end{abstract}

The purpose of this article is to examine and comment upon trends in the industrial use of gold over the past decade, particularly from the point of view of changes brought about by economic influences. It is not intended to be a detailed review of technological developments - such aspects are dealt with regularly in Gold Bulletin and elsewhere - but aims to show how economic forces can dictate changes in user attitudes and behaviour.

The broad categories of industrial and commercial use of gold that are discussed are shown in Table I. Before proceeding to examine in detail the trends displayed in this Table, it is worth clarifying the nature of the data that will be referred to throughout this article. Two particular points of definition need to be noted.

Product fabrication is defined here as the transformation of gold in bar form to semi-manufactured or final products for industrial or commercial use. Within the fabrication category there is further subdivision to indicate gold use in carat jewellery manufacture (gold content greater than one third by weight), electronics, dentistry, miscellaneous industrial and decorative uses, medals and medallions and, finally, official (legal tender) gold coins.

The second point of definition is that the industrial use of gold is assessed, for the categories described, at the point of fabrication rather than the point of use. Thus, for example, jewellery fabrication in Italy is predominantly to fulfil export orders, while plating salts manufactured in countries such as Germany and the United Kingdom are often destined for overseas customers. In each case gold use is counted at the initial point of bullion transformation.

\section{The Major Industrial Uses of Gold}

The figures in Table I show that the use of gold in commercial and industrial applications varies considerably from year to year, both in terms of overall quantity and also within different categories. After climbing to a peak of 1383 tons in 1971, total fabrication fell to 729 tons in 1974 and then more than doubled to a new high of 1552 tons in 1978.

In each year except 1974 the manufacture of carat gold jewellery claimed the greatest share of private market fabrication. In most years jewellery fabrication accounts for around two thirds of total fabrication; the proportion was 64 per cent in 1978, for example. As jewellery manufacture is such an important component of the total, the factor's which influence jewellery offtake have a very significant bearing on the overall use of gold for industrial or commercial purposes. Some of the more important influences are discussed later.

Within the other categories, gold use in electronics increased by 50 per cent to 127 tons from 1968 up to the boom year of 1973 and then was almost halved to 67 tons in 1975; it has recovered only part of the lost ground since then. Gold use in dental work and in other industrial and decorative applications has shown less variability, although dental uses have increased healthily during the past three years. Gold absorbed in the manufacture of medals, medallions and fake coins has remained at around 40 to 50 tons with the exception of the $1973 / 75$ period when fake coin manufacture in the Middle East declined sharply in the face of high bullion prices. Some replica coins were remelted during this period, which also reduced net offtake. (Fake coins can be defined as imitations of correct mass and fineness. Their maker draws his profit from the considerable price differential that may exist between the market value of official bullion coins and the value of the gold contained in them).

The great success story of the past decade has been in the 'official coins' category. The 1974 surge in worldwide investment interest in gold found expression for many investors in the bullion coins. The principal coin for investment purposes is now in- 
Table I

Fabrication of Gold for Industrial and Commercial Uses during the Period 1968 to 1978

\begin{tabular}{|c|c|c|c|c|c|c|c|c|c|c|c|}
\hline & 1968 & 1969 & 1970 & 1971. & 1972 & 1973 & 1974 & 1975 & 1976 & 1977 & 1978 \\
\hline $\begin{array}{l}\text { Total fabrication, } t \\
\text { of which }\end{array}$ & 1221 & 1197 & 1372 & 1383 & $1341^{\prime \prime}$ & 854 & 729 & 973 & 1380 & 1405 & 1552 \\
\hline Carat jewellery, $t$ & 912 & 904 & 1062 & 1060 & 996 & 512 & 220 & 519 & 931 & 996 & 1.001 \\
\hline Electronics, $t$ & 82 & 100 & 89 & 86 & 105 & 127 & 92 & 67 & 76 & 77 & 85 \\
\hline Dentistry, $\mathrm{t}$ & 60 & 60 & 59 & 63 & 66 & 68 & 57 & 62 & 76 & 82 & 87 \\
\hline Other industriali' & 58 & 63 & 62 & 69 & 71 & 72 & 67 & 60 & 66 & 6 & 75 \\
\hline Medals, medallions and & & & & & & & & & & & \\
\hline fake coins, $t$ & 40 & 44 & 54 & 52 & 41 & 21 & 7 & 21 & 47 & 47 & 46 \\
\hline$\because$ Official coins, $t$ & 68 & 26 & 46 & 54 & 63 & 54 & 287 & 244 & 184 & 137 & 259 \\
\hline Total fabrication as. & & & - & & & $\cdots$ & & & . & . & \\
\hline per cent & 67 & $104^{* * *}$ & $133^{* *}$ & 100 & $108^{* *}$ & 61 & 59 & 88 & 96 & 86 & 89 \\
\hline $\begin{array}{l}\text { Average gold price, } \\
\text { U.S.\$/oz. }\end{array}$ & 38.6 & 41.1 & 35.9 & 40.8 & 58.1 & 97.2 & $159.1^{\circ}$ & 161.1 & 124.8 & 147.7 & 193.3 \\
\hline $\begin{array}{l}\text { Average gold price, } \\
1978 \text { U.S.\$/oz. }\end{array}$ & 72.3 & 73.1 & 60.4 & 65.8 & 90.7 & 142.7 & 210.8 & 195.2 & 143.2 & 159.2 & 193.3 \\
\hline
\end{tabular}

- The balance of net private purchases represents gold bought in bullion form for investment purposes. This residual also includes stock changes and errors and omissions.

.- In 1969, 1970 and 1972 there were substantial net sales from private investment stocks of gold. Net private purchases lincluding tho\$se for investment) were consequently less than total fabrication.

disputably the Krugerrand, which is produced as legal tender in the Republic of South Africa and contains one troy ounce of gold $(31.1035 \mathrm{~g})$ : Actively promoted in major markets, with the great advantage of a low premium over the contained gold value, and with the development of good distribution channels, the coin has become a prime medium of investment in Europe and in the U.S.A. With further promotion of the Krugerrand in new markets, particularly in the Far East, and with the coin so firmly entrenched in established markets it is likely that gold use for coin manufacture will be sustained by the Krugerrand alone, quite apart from the success or otherwise of bullion coin issues planned by other countries.

\section{Gold Price and Industrial Demand}

Part of the explanation for the large changes in gold use between sectors over time lies in the competition between investors and commercial users for supplies of gold that are limited. At times of high investment interest, prices are driven sharply upwards as supplies are bid away from the industrial market. The most striking example of this occurred in the period 1973 through to 1975 .

On the commercial demand side the sensitivity of consumers to gold price changes has been the subject of much debate and occasional worthwhile analysis, but there is no simple relationship. Statistics indicate that at high prices, purchases of gold for jewellery and industrial purposes tend to decline, but the effects vary depending upon particular product types and, still more disconcertingly, price sensitivity may not be stable over time. Also, the limited evidence available suggests strongly that income effects are at least as important as price; certainly this is true in industrial nations.

Relationships between industrial demand and gold price and between industrial demand and real changes in gross domestic product are shown in Figure 1 for the most important end-use, carat gold jewellery manufacture. Despite statistical quirks the message is simple. Higher gold prices, in real terms, tend to discourage jewellery offtake and increased real incomes tend to encourage it. The point of balance between the volume of gold used on the one hand and price and income changes on the other hand is probably a moveable fulcrum which is influenced by a host of other factors, including fashion, marketing and promotional expertise, and the general availability and appeal of gold in a changing economic environment.

One further difficulty associated with statistical analysis of the price/demand relationship, and which is often ignored in simplistic studies, is illustrated in Figure 2. This shows monthly average gold prices over the January. 1976 to March 1979 period and data 

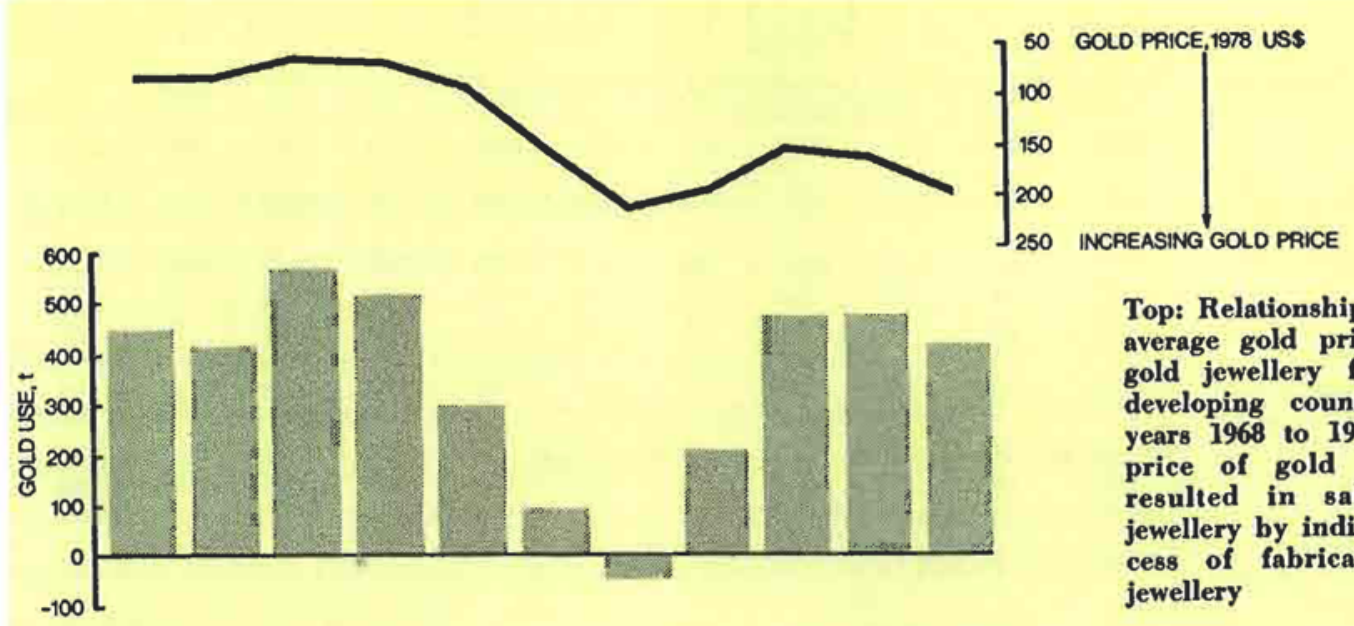

Top: Relationship between the average gold price and carat gold jewellery fabrication in developing countries for the years 1968 to 1978 . The high price of gold during 1974 resulted in sales of used jewellery by individuals in excess of fabrication of new jewellery

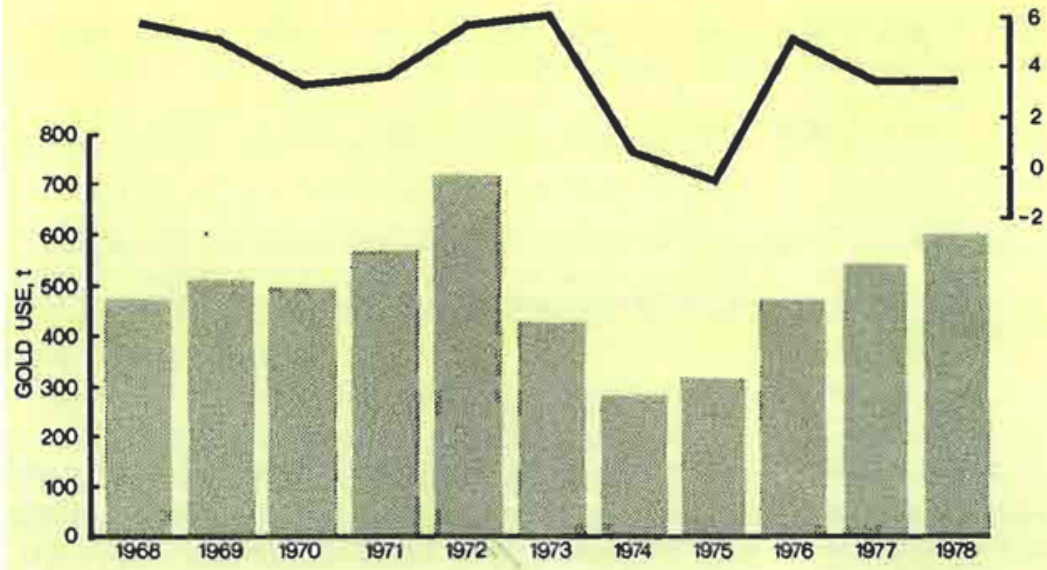

\section{REAL GOP CHANGE
RELATIVE TO PRECEDING YEAR, PER CENT}

Bottom: Relationship between real gross domestic product (GDP) changes and carat gold jewellery fabrication in developed countries for the years 1968 to 1978

Fig. 1 Illustration of the effects of gold price and variations in income (as reflected by changes in gross domestic product) on the industrial demand for gold in jewellery fabrication

consist of the average international price in dollars and in Special Drawing Rights as well as the average Japanese wholesale price. This latter variable mirrors changes in the international dollar price and the dollar/yen exchange rate, but is also influenced by local market conditions in Japan. In a similar way the price of gold to consumers in countries other than Japan and the U.S.A. has varied in line with exchange rate movements relative to the dollar and with local inflationary trends. At best therefore, a simple model which uses dollar prices, adjusted for inflation in the U.S.A., can only attempt to measure the average response of consumers to jewellery purchases.

Price effects are not confined to the jewellery industry. Higher gold prices have intensified efforts to economize in many industries. In the electronics industry, for example, the rapid escalation in prices in 1973 and 1974 led to a marked decrease in the overall use of gold despite concurrent very large increases in the volume of output by the industry. Savings were effected in two main ways: by substitution with alter- native materials and by reducing the volume of gold used for individual applications. It is probable that the scope for economizing in gold use per unit of output is now considerably less than during the previous gold price boom in 1973/74. To take just one example to support this thesis is hardly conclusive evidence, but it does illustrate a trend. The plating of high reliability connectors absorbs a good proportion of the total gold used in the electrical and electronics industries. For critical applications, such as defence, the standards are higher with respect to coating thickness and finish and also with regard to quality assurance procedures. But even there the specifications for coating thickness have been reduced. To some extent the standards required vary from region to region. End-users in the U.S.A. now require a coating thickness of only $2 \mu \mathrm{m}$ whereas ten years ago this was $5 \mu \mathrm{m}$. In Europe, a thickness of $3 \mu \mathrm{m}$ has recently been accepted for some applications; previously $5 \mu \mathrm{m}$ was also the norm. For less critical applications the change in acceptable standard is still 
Fig. 2 Monthly average gold prices, over the period January 1976 to March 1979, expressed in index form with the initial month set at 100 . The average international price is in U.S. dollars. The price in Special Drawing Rights (SDR) il. lustrates the lesser increase of the gold price over the period considered if it is expressed in terms of a 'basket' of 16 currencies instead of dollars. The in. dex of Japanese wholesale gold prices reflects the strength of the yen during the last three years

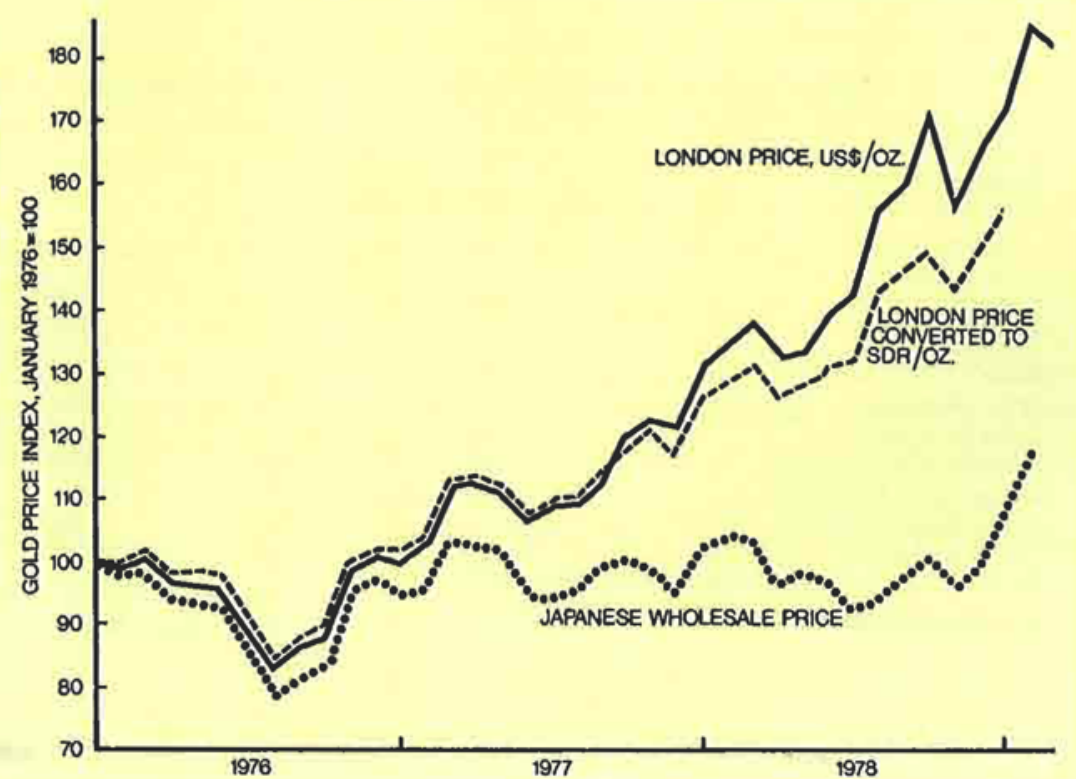

more dramatic. Connectors for light duty service which would also have been required to have a minimum gold coating of $5 \mu \mathrm{m}$ only 10 years ago are now accepted with only $1 \mu \mathrm{m}$ and sometimes as little as $0.5 \mu \mathrm{m}$ is considered satisfactory.

The impact of such changes, and there are other examples, is shown clearly by the data in Table I. The recent partial recovery in gold use in electronics probably owes more to the surge in unit output rather than to the lower average price of the metal during 1976/77. In fact, it is likely that economizing practices are still having an impact although lower gold use per unit of output has been offset to a large degree by the increased volume of production of electronic components.

Another way of looking at the price elasticity of industrial demand for gold and at the effects of technological changes is the market survey approach. Table II shows the response to two of the questions included in a regular survey (originally annually and now biennially) of a representative sample of the electronics industry in the U.S.A. Because of the international nature of most large users and suppliers of electronic components, these responses may be fairly taken as representative of the industry as a whole, although one would expect the actual yearly response in each country to differ according to its experience of gold prices expressed in local constant currency units.

A reasonable interpretation of the information in Table II is that answers to the first question show a clear relationship with the prevailing gold price in the intention to economize in the use of gold. Answers to the second question reveal that there have been delays in the implementation of these intentions. It is not

Table II

Influence of the Gold Price on Attitudes in the U.S. Electronics Industry

\begin{tabular}{|c|c|c|c|c|c|}
\hline \multirow[t]{2}{*}{ Year } & \multirow{2}{*}{$\begin{array}{c}\text { Average } \\
\text { gold price, } \\
1978 \text { U.S. } \$ / o z \text {. }\end{array}$} & \multicolumn{2}{|c|}{$\begin{array}{l}\text { If price stays at current levels } \\
\text { would you economize gold? }\end{array}$} & \multicolumn{2}{|c|}{$\begin{array}{c}\text { Does gold price affect } \\
\text { the quantity used? }\end{array}$} \\
\hline & & yes, $\%$ & no, $\%$ & yes, \% & no, $\%$ \\
\hline 1972 & 91 & & & & \\
\hline 1973 & 143 & 51 & 49 & 26 & 74 \\
\hline 1974 & 211 & 83 & 17 & 54 & 46 \\
\hline 1975 & 195 & 79 & 21 & 79 & 21 \\
\hline 1976 & 143 & 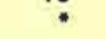 & 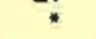 & 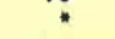 & 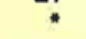 \\
\hline 1977 & 159 & 47 & 53 & 63 & 37 \\
\hline 1978 & 193 & $\because$ & 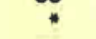 & $*$ & 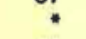 \\
\hline 1979 & 250 (est.) & $* *$ & $* *$ & ** & ** \\
\hline
\end{tabular}

- Not surveyed.

-* Results pending. 
Table III

Use (*) of Gold by Region in 1968 and 1978: Per Capita Quantities and Values

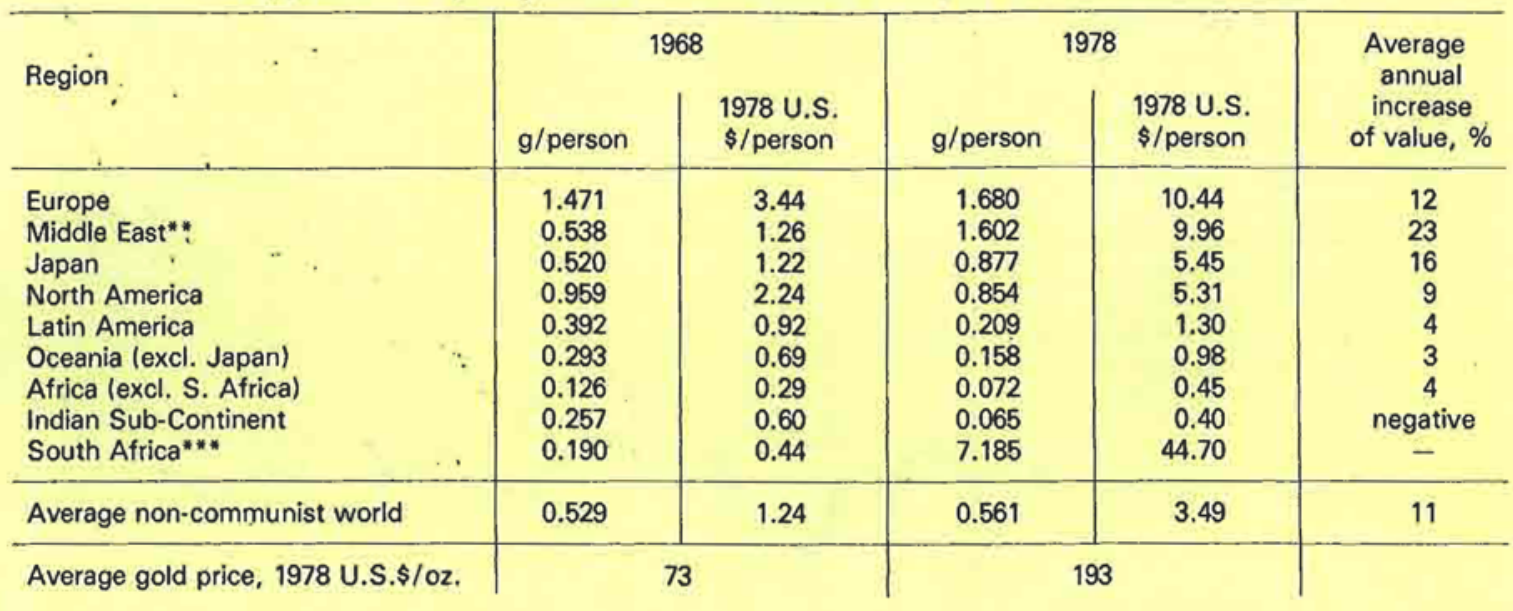

- Due to the nature of available statistical data, 'use' refers here to the transformation of bullion into manufactured or semi-manufactured products.

*. The term 'Middle East' used here encompasses a broad sweep of countries extending from Turkey in the North, through the Mediterranean coast to Egypt and eastwards to include the Gulf States and Iran. The unifying feature of the countries included being the mass manufacture of high carat, low mark-up jewellery.

"* South Africa's extraordinary per capita increase is due almost entirely to Krujerrand production, most of which is sold overseas.

possible to deduce from these data whether the technical capability of the industry to economize is exhausted, or whether some practical limit to economizing is being approached. The latter situation would probably be indicated by a steady or falling response in the 'yes' columns, regardless of variations in the gold price. In that respect it will be interesting to see the results of the 1979 enquiry.

\section{Other Factors Affecting Industrial Demand}

There are effects other than gold price and general levels of disposable income that affect gold consumption. One interesting example of non-price factors is provided by the use of gold in the manufacture of dental alloys. The ratio of the price charged to patients for gold in dental prosthesis to the market value of that gold varies widely between countries - from a little over 1 in some developing countries up to 3 or 4 in the richer industrialized countries. To some extent this reflects differences in the sophistication of dental prosthetic techniques. It also reflects the degree of support for the use of dental gold by national health services. For example, a cutback in the Medicare programme reduced offtake of dental golds in the U.S.A. in 1969/70, whereas in recent years favourable changes in state health insurance schemes have led to a very significant increase in their use in Germany and Japan.

The attitudes of the dental professional to tooth preservation and extraction also vary widely, as do social attitudes towards visible gold teeth. To some they are very appealing, while to others they are abhorrent. Factors such as these, together with inventory changes and cost, and technical substitution, account for most of the changes in the offtake of gold by the dental industry over the past ten years.

\section{The Regional Pattern of Gold Use}

The discussion so far has concentrated on the volume of gold used each year in various industries. However, an important insight into gold use and its trends can be obtained by reference to the regional pattern of consumption and also by reference to the value of the metal used, particularly with respect to changes over time.

Table III gives a regional breakdown of per capita annual gold use for the years 1968 and 1978. Mass and value data are considered and, for the latter, average annual growth rates over the stated period are also presented. Although the patterns of gold use vary from year to year, occasionally quite significantly, the two years selected for reference do give a reasonable picture of absolute levels and trends over the past decade.

Referring first to the mass of gold used, one interesting feature is that regional variations are very large, and in some cases appear to be growing still larger. To take just one example, gold use in Europe grew from $1.471 \mathrm{~g}$ per person in 1968 to $1.680 \mathrm{~g}$ in 1978, while in Africa the mass of gold used per person fell from 0.126 to $0.072 \mathrm{~g}$ over the same period. In the wealthy areas of the world, basically the industrialized nations of Europe, Japan and North 
America together with the oil-rich Middle East, the mass of gold used per capita has increased over the period, while in the poor nations it has declined. The pattern is illustrated still more clearly by considering the value of gold used in each region. Some comments are appropriate:

(1) The per capita value of gold used annually for intustrial and commercial purposes in the noncommunist world has increased from a constant 1978 dollar value of 1.24 in 1968 to 3.49 in 1978 . This represents an average annual increase of 11 per cent. (Note that fabrication only, and not investment, is considered)

(2) The average increase of 11 per cent covers a wide spectrum of growth rates between regions. In broad terms it seems that the figures demonstrate once again that the rich get richer and the poor get poorer. Apart from the spectacular 23 per cent annual increase registered in the Middle East, for reasons that are only too apparent, the growth rates tend to reflect overall regional economic performance with the growth league led by Japan followed by Europe and North America. The poorest area of the world, the Indian SubContinent, recorded a decline in the real value of gold that people in this region were able, or possibly willing, to buy

(3) In absolute terms, and again excluding the special case of the Middle East, the per capita use of gold in Europe is still almost double that in North America and Japan. This situation is thought unlikely to persist and greater than average growth rates in per capita use in the U.S.A. and Japan are anticipated over the next few years.

Of course such statistics as these can be misleading in a number of ways. Regional consumption figures rather than 'use' data would change the picture somewhat, Jewellery manufacture in Italy, for example, is mostly for export and much is for the North American market. Hence, the figures as presented understate per capita spending in gold in the U.S.A. and overstate it in Europe. Also, exchange rate fluctuations between local currencies and the dollar could affect the analysis. Several other such anomalies could be given.

In addition to this, there is a grave temptation to oversimplify the marketing value of such information. For example, having been presented with the 1968 data in 1969 and then asked for an opinion as to the most promising area for market growth, how many would have opted for the Middle East? How many for Latin America on the basis of the oftpostponed Brazilian miracle?

However, the broad conclusions are quite clear and would be unaffected by more elaborate calculations. First, the value of average per capita private gold pur- chases for fabrication has grown at an annual real rate of 11 per cent over the 1968 to 1978 period while the equivalent average growth in the world total of gross national products was less than 2 per cent. Secondly, in the wealthier regions of the world, both growth rate in gold use and the absolute level of gold use are greater than in the poorer regions of the world.

\section{Future Trends in Gold Use}

As to the future one must address the questions: why are people willing to spend more on gold now than they did ten years ago and will this tendency continue?

Clearly, from the restricted list of influences discussed earlier, a complete answer to the first question is not possible; the complex interaction of various factors defies exhaustive analysis. The best that can be hoped is that the major variables can be identified and, in part, their influence measured. Three factors appear major contributors to the heightened attraction of gold relative to other goods and services:

(1) Sustained inflationary pressures which have led to a search for investment instruments appearing to maintain real wealth. Gold jewellery sales have benefited from this quite as much as private coin or bullion sales to investors

(2) Increased real disposable incomes in the developed world and in some developing countries. Such increases in wealth have facilitated increased purchases of non-essential goods and services. Again jewellery and decorative applications of gold have benefited

(3) The technical merits of gold as an industrial metal. At least one industry making use of these merits, electronics, is likely to have above average growth.

Looking to the future, over the next ten years say, it is reasonable to assume that persistently high levels of inflation will be incompatible with continued strong growth in real incomes. But it is tempting to conclude with a 'heads I win, tails you lose' view of the gold industries' prospects. If inflation, then a scramble for bullion investment; if sustained real economic growth, then increased use of precious metal to decorate and provide services for ever more affluent members of society. The main danger to such a sanguine view of gold's future lies in the possibility of a major economic setback brought about largely as a consequence of world financial imbalances. In such circumstances, analagous to the worldwide depression last experienced in the 1930's, cash again becomes desirable, prices in general tend to fall and real disposable incomes decline sharply. Such then are the possibilities, it is a matter for individual judgement which economic path will eventuate. 